on an instrumented climbing wall. Oxygen consumption $\left(\mathrm{VO}_{2}, 1 / \mathrm{min}\right)$ was measured with a portable battery-powered Cosmed $\mathrm{K}_{4} \mathrm{~b}^{2}$ metabolic systems via open circuit indirect calorimetry and the movement sequence with time was identified from the force signals at different holds. The results show that the fluctuations of $\mathrm{VO}_{2}(1 / \mathrm{min})$ are synchronised with climbing and depend on the route conditions, which, in turn, require different climbing techniques. The cyclic behaviour of respiration provoked by a circular boulder route suggests that the oxygen uptake is influenced by the climbing route even after the steady state is reached.

\title{
56 RESPIRATORY RESPONSE TO DIFFERENT PARTS OF A CLIMBING ROUTE
}

G Balasekaran, ${ }^{1}$ F K Fuss, ${ }^{2}$ G Nieg| ${ }^{3}{ }^{1}$ Nanyang Technological University, National Institute of Education, Physical Education and Sports Science, Singapore; ${ }^{2}$ Sports Engineering Research Team, Division of Bioengineering, School of Chemical and Biomedical Engineering, Nanyang Technological University, Singapore; ${ }^{3}$ Department of Anthropology, University of Vienna, Vienna, Austria

10.1136/bjsm.2010.078725.56

This study investigates the fluctuations of oxygen uptake in synchrony with repetitive climbing a circular boulder 